\title{
Developing Agricultural Products Logistics in China from the Perspective of Green Supply Chain
}

\author{
Dan $\operatorname{Tan}^{1,2}$ \\ ${ }^{1}$ School of Economics, Central South University of Forestry and Technology, Hunan, China \\ ${ }^{2}$ School of Transportation and Logistics, Central South University of Forestry and Technology, Hunan, China \\ Correspondence: Dan Tan, School of Economics, Central South University of Forestry and Technology, No.498 \\ South Shaoshan Road, Changsha, Hunan, China. Tel: 86-137-8741-8695. E-mail: newtandan@gmail.com
}

Received: August 14, 2012 Accepted: September 29, 2012 Online Published: October 23, 2012

doi:10.5539/ijbm.v7n21p106 URL: http://dx.doi.org/10.5539/ijbm.v7n21p106

\begin{abstract}
The circulation channel of agricultural products in China is complicated and unstable. The external negative effects of exhaust emission, noise pollution, waste of resource, traffic congestion, and wastage exist in the process of the agricultural products logistics. The green supply chain of agricultural products is a good solution to the problem. Based on the theory of green supply chain and supply chain of agricultural products, this paper analyzes the content and requirements of green supply chain of agricultural products, and proposes organizational system and the mathematic model of the development of green supply chain of agricultural products. Given the characteristics of China's traditional agricultural products logistics and the perspective of green supply chain, developing countermeasures of agricultural products logistics in China are provided from the aspects of the benefits allocation principles and the quality safety control system of agricultural products.
\end{abstract}

Keywords: agricultural products logistics, green supply chain, mechanism

\section{Introduction}

China is a large agricultural nation, and agriculture is the fundamental industry of national economy. The production, exchange, distribution and consumption of agricultural products constitute the organic chain of agriculture reproduction. Any deficiency of them will affect the development of agriculture. However, the circulation channel of agricultural products in China is complicated and unstable. There are no normative system management and control, and also lacking the attention to the safety of agricultural products and environment protection. With the improvement of standard of living, Chinese has higher requirements on the safety and quality of the agricultural products. However, the numerous participants, large quantities, extensive variety and high cost of agricultural products logistics decide the difficulty of logistics and the vulnerability of supply chain. Moreover, the huge "external negative effect" of exhaust emission, noise pollution, waste of resource, traffic congestion, and wastage exists in the process of the logistics. In order to solve these problems, green supply chain of agricultural products need to be constructed, tightly and organically connecting the production material supplier, the producer, the processor, the logistics service provider, the wholesaler, the retailer and the consumer, which can guarantee the quality safety of agricultural products, reduce the logistics cost, achieve the objectives of optimum distribution of resources, promotion of welfare and environment protection, propel the development of China's agricultural products logistics in green way.

\section{Literature Review}

\subsection{Green Supply Chain Management}

The concept of green supply chain management was firstly put forward by Manufacturing Research Centre of Michigan State University in 1996, which focused on the attention to environment impact and optimizing utilization of resource of the manufacturing supply chain, with the purpose of minimizing the negative environment impact caused by supply chain and maximizing the efficiency of resource utilization. This theory was mostly used in the supply chain management of manufacturing. The relative research emphasized on the design and structure, environment evaluation of environment impact, the strategic implementation, green purchase, total quality environmental management, green marketing, and enterprise performance of the green supply chain management. Sarkis Joseph (1998) pointed out, green supply chain includes the internal logistics 
of enterprise, materials management, external logistics, packing and reverse logistics. M. H. Nagel (2000) put forward that the green supply chain covered the whole process of the production and utilization. He emphasized on the construction of a stable and long-term strategic relations in the scope of the whole supply chain. The view of Jeremy Hall (2000) was rather comprehensive. He regarded the green supply chain as the ecological design for the whole process of raw material purchase, production, consumption, and waste recycle in supply chain, with the purpose of sustainable development of society and enterprises. Through the tight cooperation of the enterprises and internal department, the green supply chain could achieve harmonization of environment management and optimization of systematic environment. With the development of the theory and practice examination, the content of green supply chain was enlarged. Not only the manufacturing activities and product conversion activities were included, but also the environment design, improvement of operating process of provider, and evaluation system were covered. The supply chain and environment were gradually integrated. Sarkis J. (2003) developed analytic network process of decision making technique in his research. According to his view, the operating decision of green supply chain was mainly influenced by the state of product life cycle, the activities of enterprise in the supply chain, the environment awareness activities (reduction, reproduction and recycle), the requirements of organizational performance, and the optional systematic measures.

In China, the theoretical system of green supply chain management was not formed thoroughly. The published articles focused on the introduction of the content, development, enforcement characteristics, strategic mode, and systematic structure of green supply chain. For example, Yinluo Wang, Nengming Wang and Linyan Sun (2003) considered the green supply chain management as an effective solution to the conflicts between manufacturing industry and environment. They put forward the conceptual model of green supply chain from the perspective of sustainable development, analyzed the objectives of green supply chain management, and discussed the basic principles of green supply chain management. Qinghua Zhu (2004) constructed the dynamic impact model of green supply chain management for China's manufacturing enterprises by using factor analysis method. Nengmin Wang, Tong Yang, Jianming Qiao (2007) discussed the obstacles of the implementation of green supply chain from the aspects of externality, self-serving behavior of supply chain members, and information asymmetry. They thought that the coordination was the basis of green supply chain implementation.

\subsection{Agricultural Products Supply Chain}

With the development of modern agriculture, agricultural products supply chain attracted the interest of scholars both in other countries and in China. According to foreign scholars, in the process of "from field to dining table", agricultural products supply chain indicated the evident characteristics of nonlinear system, which could be called Producers and consumers dual drive mode. Chinese scholars did a lot researches on the fresh agricultural products supply chain, the existing organizational structure of agricultural supply chain, traceability system of agricultural supply chain, and the agricultural supply chain in E-commerce. Yubo Wang, Shihua Ma (2004) discussed the agricultural products supply chain management in the process of agriculture industrialization of China. Tao Tan, Yihua Zhu (2004) put forward the organizational structure of agricultural products supply chain, taking the processing enterprises and logistics enterprises as the center of supply chain. Dinghuan Hu (2007) pointed out the needs of effective control of producing, processing and circulating process of agricultural products. The traceability system of agricultural products needed to be established on the basis of supply chain management. These researches did helpful exploration of the construction and implementation of agricultural products supply chain, but did not integrate the theory of green supply chain into the management of agricultural products supply chain.

\subsection{Green Supply Chain of Agricultural Products}

In recent years, some scholars started to pay attention to the importance of green supply chain of agricultural products. Bolan Zhong (2008) proposed the definition of green supply chain of agricultural products. Chunxiao Wang, Yue Chen (2008) put forward the five aspects of green supply chain management in circular agriculture, which were green production, green transportation, green processing and circulation, green consumption and green recycle. The relative evalution system also was provided in their relative researches of circular agriculture. Qingtao Li (2010) analyzed the necessity of implementing green supply chain management of agricultural products in China, and proposed some relative measures. However, the researches were still in the initial state. Further studies based on the concept of green supply chain management of agricultural products, to explore the effective countermeasures of developing China's agriculture products logistics in green way were needed. 


\section{The Mechanism of Green Supply Chain of Agricultural Products}

\subsection{The Characteristics of Traditional Agricultural Products Logistics in China}

In China, the logistics cost of agricultural products takes up $40 \%$ of the total cost. For fresh agricultural products, this figure is up to $60 \%$. In other developed countries, the logistics cost is about $10 \%$. The loss rate of agricultural by-products, such as fruit and vegetables, is $25 \%$ to $30 \%$ in the process of picking, transportation and storage. The gross loss is amount to hundred billion a year. In American, the loss rate of agricultural products in the process of processing and transportation is only $1 \%$ to $2 \%$. In China's traditional agricultural products logistics, peasant household, agricultural products producer and processor, wholesaler, and retailer are in the loose connection. They pursue their own profit maximization and compete with each other. The cost reduction and profit increase are partly based on the harm of other's benefits. Sometimes, they cooperate with others, but the cooperation is in the short term.

\subsection{The Analysis of Agricultural Products Supply Chain}

Agriculture is an intertexture industry of natural reproduction and economic reproduction. The essential attribute of agricultural products production decides the agricultural products supply chain is different from manufacturing industry supply chain. The efficiency enhancement of agricultural products circulation mainly depends on the concerted efforts from the node enterprises in the supply chain. Agricultural products supply chain breaks the border of single enterprise, integrates the material flow, information flow, capital flow of all the enterprises in the supply chain, sharing information, encouraging collaboration, developing strategic cooperation partner relations in the long term, with the purpose of reducing the logistics cost and improving the quick-reaction capability of logistics.

Agricultural products supply chain is a self-organizing system, influenced by the internal and external environment. As time goes on, some factors decide the evolutive direction of the whole system more and more evidently, which are order parameters. The self-organizing system has the initiative of adapting and selecting the order parameters, which means the node enterprises could adjust and cooperate actively, weakening and assimilating some undesirable order parameters, increasing and developing some desirable order parameters. As a result, the synergy among node enterprises, the synergy between the supply chain and environment can be realized, and the efficiency of the supply chain can be improved. Under some conditions, the subsystems of the supply chain can form some self-organizing structure and present new ordered state through the non-linear interaction among them. In the process of organizing, the system is influenced by many factors, but some factors always decide the evolution and operating results of the system.

\subsection{The Content, Requirements and Organizational System of Green Supply Chain of Agricultural Products}

Based on theory of green supply chain management and under the guidance of sustainable development, taking environment protection, quality safety guarantee and economic benefits increase as the organizational objectives, the green supply chain of agricultural products means the integration of activities of the purchase, production, classification, processing, packing, distribution, transportation, storage, consumption and recycling of the agricultural product. It requires the design of some rules and procedures under the circumstances of incomplete information, to establish strategic cooperative partner relations among the production material supplier, peasant household, standardization planting base, agricultural enterprise, distribution center of agricultural products, wholesale market, supermarket, farmer's market, retailer and consumer, forming the incentive and compatibility system. This system enjoys well-organized internal cooperation and competition and well-integrated external environment. The quality safety of agricultural products is guaranteed and the operating cost of supply chain is reduced. The negative environmental impact is decrease and the maximization of the system benefits is achieved. The organizational system of the green supply chain of agricultural products is in the below. (See figure 1)

\subsection{The Mathematic Model of the Development of Green Supply Chain of Agricultural Products}

According to the above system, the function of the development of green supply chain of agricultural products can be constructed. The independent variables are the development factors of agriculture production, synergetic development factors of enterprises, and the development factors of green technology. The function is:

$$
F=f(A, E, T)+\varepsilon
$$

$\mathrm{F}$ stands for the function of development of green supply chain of agricultural products; A stands for the variables of the development level and influencing factor of agriculture production; E stands for the variables of the synergy level and influencing factor of enterprise; $\mathrm{T}$ stands for the variables of the development level and influencing factor of green technology; $\varepsilon$ stands for the disturbance caused by the unpredictable external factors. 
The mechanism of action and the influencing characteristics of these influencing factors are similar to the input and output relations between capital and labor force of the Cobb-Douglas production function. Moreover, the Cobb-Douglas production function is widely used as the tool of analyzing the factors of economic growth. Therefore, based on the Cobb-Douglas production function, this paper improves the mathematical model of the development of green supply chain of agricultural products as:

$$
F=f(A, E, T)+\varepsilon=k\left(A^{\alpha}, E^{\beta}, T^{\gamma}\right)+\varepsilon \quad k>0
$$

$\alpha, \beta, \gamma$ stand for the coefficient of elasticity of A, E, T respectively, presenting the quantity of impact of green supply chain of agricultural products received from various factors. $k$ stands for the comparable adjustment coefficient of agricultural products logistics in different period.

The development utility and level of green supply chain of agricultural products can be assessed by this model. The nonlinear least square method can be used to get the results of $\alpha, \beta, \gamma$, and then, the development utility and level in a certain period can be determined and compared.

\section{The Benefits Allocation Principles of Green Supply Chain of Agricultural Products}

According to David Ricardo, the main problem of plutonomy is to decide the governing rules of allocation. The establishment of the scientific, reasonable and effective principles of benefits allocation is not only favorable for the maintenance of the cooperative partner relations, the realization of the effective allocation of total resources, the increase of supply chain efficiency, but also desirable for the guarantee of the security and stability of supply chain.

However, the numerous members in the green supply chain of agricultural products have different division of work, different position, and different contribution rate to overall benefits. The realization of the overall benefits is influenced by the rapidly changing environment factor, market factor and internal factor, which lead to big uncertainty. The expectation and awareness of the benefits allocation are different for different members, due to different environment, position, corporate culture, value, and information. These characteristics decide the benefit allocation of green supply chain of agricultural products is very complicated. The relations among members need to be well adjusted. The allocation principles need to be established according to the comprehensive contribution rate of different members achieved to the strategic objectives of the green supply chain of agricultural products, which are environment protection, quality safety and economic benefits growth. The principles in the below can be followed in the benefits allocation of green supply chain of agricultural products.

(1) Utility principle. Suppose, the number of the cooperative members in the supply chain is $n$, the vectors of two scheme of benefits allocation are $P_{1}=\left(V_{11}, V_{12}, \cdots V_{1 n}\right), P_{2}=\left(V_{21}, V_{22}, \cdots V_{2 n}\right)$, the utility function of member $i$ is $U_{i}\left(V_{i}\right)$.

Let $M_{1}=\prod^{n} U i\left(V_{1 i}\right), M_{2}=\prod^{n} U i\left(V_{2 i}\right)$

If $M_{1}>M_{2}^{i=1}$, then allocation schème $P_{1}$ is better than $P_{2}$

(2) Input principle. Suppose, the inputs $I_{i}$ of member $i$ are more than the input $I_{j}$ of member $j$, then the benefits $V_{i}$ of member $i$ are more than the benefits $V_{j}$ of member $j$. That is, if $I_{i}>I_{j}$, then $V_{i}>V_{j}$

(3) Risk principle. Suppose, the risks $\mathrm{R}_{i}$ taken by member $i$ are higher than the risks $\mathrm{R}_{j}$ taken by member $j$, then the benefits $V_{i}$ of member $i$ are more than the benefits $V_{j}$ of member $j$. That is, if $R_{i}>R_{j}$, then $V_{i}>V_{j}$.

(4) Equality principle. Regardless of the size, the strength, the position in the supply chain of the members, each member has the equal right to pursue their profits, according to their contribution to the supply chain.

(5) Concession principle. In the process of benefits allocation, some new benefits, which are not or not clearly stipulated in the agreement of benefits allocation, maybe emerge in the practice. The allocation of this part benefits should be based on the thoughts of mutual benefit and reciprocity, and full consultation. When the actual benefits allocation is evidently in favor of some member, this member can make some concession and give part of the benefits to those members who received fewer profits. In this way, the mutual development can be achieved. 


\section{The System of Quality Safety Control of Agricultural Products}

\subsection{The Establishment of Market Entry Standard and Quality Control Tracing System}

The establishment of the agricultural products quality management system, covering the whole process of material supply, production, storage, processing, packing, distribution, marketing and consumption, can realize the traceable source, trackable flow, storable information, and recallable products of agricultural products in different form, different property rights transfer, and different link of management.

First, the agriculture inputs need to be utilized scientifically by establishing the announcement system of restricted inputs, so as to decrease the pollution of chemical fertilizer, pesticides, and feed additive on the agroecological environment and agricultural products. Based on the scientific evaluation of the place of production environment, the monitoring plan of the place of production environment of agricultural products needs to be implemented, strictly controlling the pollution from the industrial wastes and household garbage. Second, the short sight of some peasants of pursuing short term profits can be fundamentally changed through constructing the registration system of production file, making the producer record and store the information about the place of production environment, the utilization of agriculture inputs, field management, and the producer, ensuring the information can be traced in subsequent procedure, identifying the quality responsibility of producer. Moreover, the code of the place of production, the product code, the production file, and the pacing mark can be organically connected through the certification of agricultural products, label verification, label coding management, and label information inquiry. Then, the tracing link of agricultural products from fields to dining table becomes complete.

5.2 The Popularization of Economical and Convenient Detection Technology for Agricultural Products Quality Safety

As the result of comprehensive function of analytical technology, biological technology and information technology, the quick test technology has the advantages of short time, low cost, easy and on-spot operation. It is suitable for the most serious problems, existing in the process of monitoring quality safety of agricultural products at present, such as pesticide residue and heavy metal in the soil environment. In consideration of the income level of Chinese peasants, it is also a practical solution to guarantee the quality safety of agricultural products.

\subsection{The Sharing of Scattered Detection Resource through Network}

Due to the limitation of user's qualification and capability, some complicated detection technology is difficult to popularize, for example, the near infrared spectroscopy analysis technology. The model construction of this technology needs to collect plenty of representative samples, and needs to be accomplished by professionals who are familiar with the knowledge of spectum, chemometrics and analysis. Obviously, the common users do not have such conditions. This kind of problem can be solved by sharing the detection resources through network. The network center of near infrared spectrum is responsible for the construction and update of the model. The model is transferred to user through network. The user can apply this technology conveniently only by transferring the spectrum and character of samples to network center. There is no need of constructing model by user, which saves abundant time and money.

\section{Acknowledgements}

This paper is financially supported by the project (No: 2012ZK3168) of Hunan Provincial Science\&Technology Department, the project (No: 10C1300) of Hunan Provincial Education Department, and the project of Youth Science Foundation of Central South University of Forestry and Technology. 


\section{References}

Bo, L. Z. (2008). Constructing Green Supply Chain of Agricultural Products. Logistics Sci-Tech, 4, 48-50.

Chun, X. W., \& Yue, C. (2008). Green Supply Chain Management of Agricultural Products based on Thoughts of Circular Economy. Prices Monthly, 3, 30-31

Ding, H. H. (2007). Construction and Perfection of Tracing System of Agricultural Products. China Agricultural Information, 3, 8-9.

Hua, J., Tao, S., \& An, X. L. (2008). Geo-statistical Analysis and Evaluation of Soil Heavy Metal Pollution on a Field Scale. Transactions of the Chinese Society of Agricultural Engineering, 11, 226-229.

Hui, X. Z. (2006). Supply Chain Collaborative Management: Theory and Metheod. Beijing, BJ: Beijing University Press.

Jeremy, Hall. (2000). Environmental Supply Chain Dynamics. Journal of Cleaner Production, 8, 455-471. http://dx.doi.org/10.1016/S0959-6526(00)00013-5

Nagel, M. H. (2000). Environmental Supply Chain Management versus Green Procurement in the Scope of a Business and Leadership Perspective. IEEE2000(2).

Neng, M. W., Tong, Y., \& Jian, M. Q. (2007). Study on Green Supply Chain Management. Industrial Engineering, 1, 11-16.

Qian, Z., \& Chong, G. L. (2008). The Supply Chain Management Mode and Countermeasures of Agricultural Products Logistics Development. Soft Science, 1, 91-93

Qing, H. Z. (2004). Green Supply Chain Management. Beijing, BJ: Chemical Industry Press.

Qing, T. L. (2010). Initial Discussion of Green Supply Chain of Agricultural Products. Logistics Engineering and Management, 4, 101-106.

Sarkis, Joseph. (1998). Theory and Methodology: Evaluating Environmentally Conscious Business Practices. $\begin{array}{lllll}\text { European Journal of } & \text { Operational 159-174. }\end{array}$ http://dx.doi.org/10.1016/S0377-2217(97)00160-4

Sarkis, Joseph. (2003). A Strategic Decision Framework for Green Supply Chain Management. Journal of Cleaner Production, 11, 297-409. http://dx.doi.org/10.1016/S0959-6526(02)00062-8

Shan, L., He, B. S., \& Guang, X. W. (2009). Synergistic Model Design for High Qualilty Pork Supply Chain. Science and Technology of Food Industry, 8, 343-345.

Tao, T., \& Yi, H. Z. (2004). Study on the Organizational Mode of Agricultural Products Supply Chain. Modern Economic Research, 5, 24-27.

Xiao, F. Z., \& Chong, G. L. (2008). Research on Profit Distribution Model and Tactics for the Agro-Product Supply Chain Alliance. Soft Science, 5, 90-94.

Yin, L. W., Neng, M W., \& Lin, Y. S. (2003). The Principles of Green Supply Chain Management. Chinese Journal of Engineering, 11, 82-87.

Yu, B. W., \& Shi, H. M. (2004). Ideas of Primary Products Supply Chain Management in China Agro-industrialized Tenor. Logistics Technology, 11, 47-50. 


\section{Appendix}

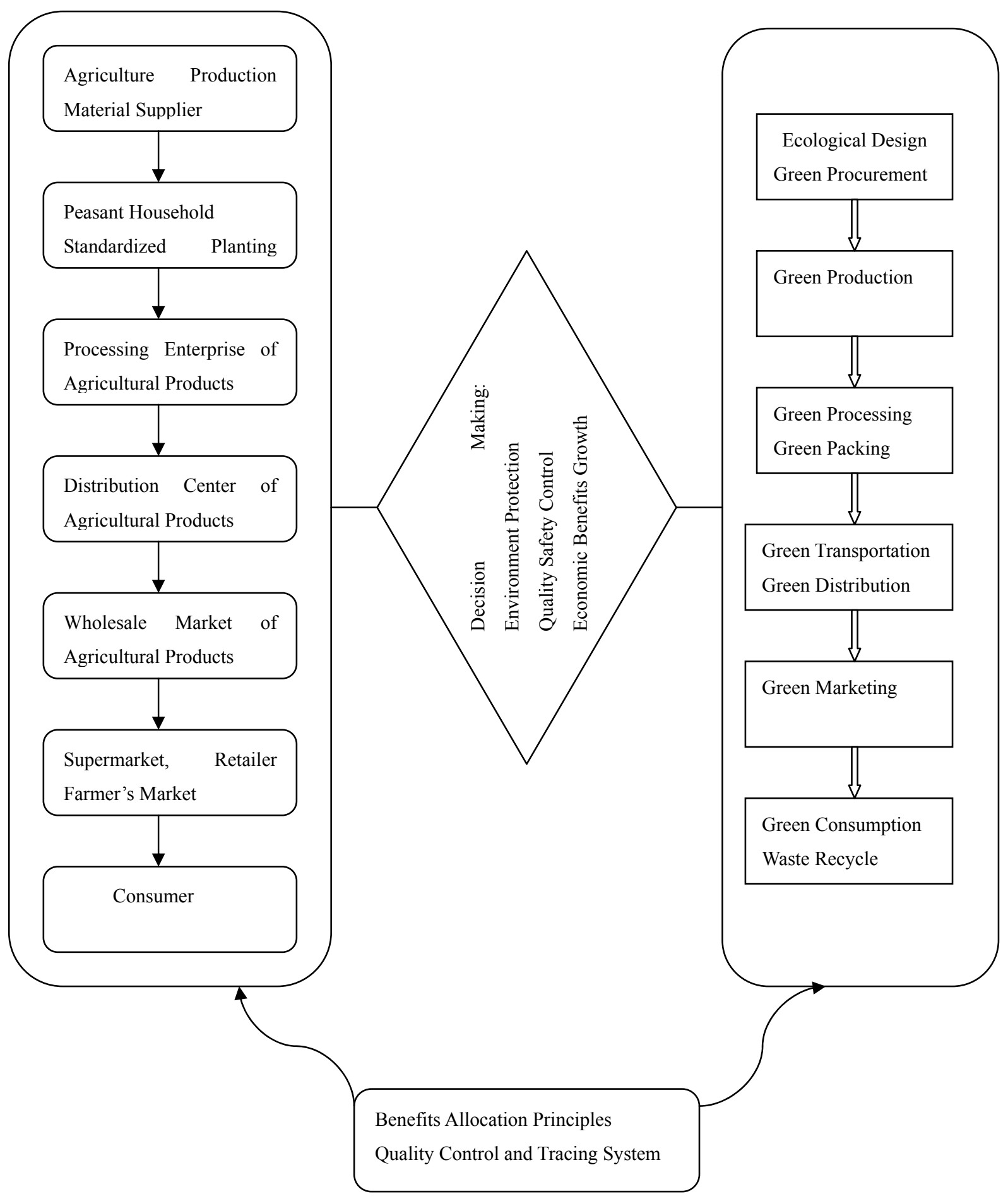

Figure 1. The organizational system of green supply chain of agricultural products 